\title{
KOMUNIKASI DAN DAKWAH PADA LEMBAGA PENDIDIKAN ISLAM
}

\author{
Imron Muttaqin \\ IAIN Pontianak, Indonesia \\ Email: imron.muttaqin@gmail.com
}

\begin{abstract}
ABSTRAK
Communication and da'wah are play an important role in the success of Islamic education institutions. Communication is the process of delivering ideas that are horizontal, vertical or diagonal. Effective communication efforts can be carried out by fulfilling all elements of communication consisting of communicators, messages, channels, sources, and effects. In addition, it is necessary to take a persuasive approach and emotional closeness by increasing communication skills for da'wah. The form of effective communication at educational institutions is inter-professional-collaborative communications, associative-accommodative and interpersonal communication, this form of communication must be adapted to the shared of organizational culture.
\end{abstract}

(Komunikasi dan dakwah sangat berperan pada kesuksesan lembaga pendidikan Islamkomunikasi merupakan proses penyampaian ide, gagasan baik yang bersifat horizontal, vertikal atau diagonal. Upaya komunikasi yang efektif dapat dilakukan dengan memenuhi semua unsur komunikasi yang terdiri atas komunikator, pesan, channel, sumber, efek serta sumber komunikasi. Selain itu perlu melakukan pendekatan persuasif dan kedekatan emosioanal dengan meingkatkan keahlian berkomunikasi untuk dakwah. Bentuk komunikasi efektif pada lembaga pendidikan adalah komunikasi adalah komunikasi interprofesionalkolaboratif, komunikasi asosiatif-akomdatif dan interpersonal, bentuk komunikasi ini harus disesuaikan dengan budaya organisasi yang dianut bersama).

Kata Kunci: Komunikasi, Dakwah dan Pendidikan Islam

\section{PENDAHULUAN}

Sebagai proses sosial, komunikasi mempunyai peran penting untuk menyatakan maksud dengan komunikan. Berdasarkan hasil penelitian, komunikasi organisasi, motivasi kerja dan kompensasi secara bersama-sama berpengaruh signifikan terhadap kinerja guru. ${ }^{1}$ Oleh karena itu komunikasi dalam organisasi pendidikan

\footnotetext{
${ }^{1}$ Wijaya, D. K., \&Herminingsih, A. (2015). Pentingnya Komuniksi Organisasi, Motivasi Kerja dan Kompensasi untuk Meningkatkan Kinerja Guru. JEAM Vol. XIV. ISSN: 1412-5366 e-ISSN: 2459, 9816.
}

perlu terus dipelihara dan ditingkatkan kualitasnya agar semakin baik. Peran penting komunikasi pada lembaga pendiddikan Islam juga menentukan terlaksananya fungsi-fungsi manajemen. Komunikasi menurut Gibson adalah a) komunikasi kebawah, b) komunikasi keatas, c) komunkasi horizontal dan d) komunikasi diagonal. ${ }^{2}$ Komunikasi kebawah adalah komunikasi yang

${ }^{2}$ Gibson, James L, John M. Ivancevic, Hames H. Donnely, Jr. 1997. Organisasi, PerilakuStruktur-Proses), Edisi 8. Jilid 2. Terjemahan Nunuk Adrinani Jakarta: Bina Rupa Aksara, h. 241. 


\section{Imron Muttaqin}

Komunikasi dan Dakwah Pada Lembaga Pendidikan Islam

dilakukan oleh struktur yang lebih tinggi kepada yang lebih rendah, komunikasi ini bisa disampaikan dengan tertulis maupun secara lisan. Jika disampaikan tertulis dapat berupa memo, surat tugas, surat perintah dan sebagainya. Komunikasi keatas dilakukan dengan cara memberikan saran baik lisan maupun tertulis, melalui forum-forum, pertemuan, rapat, musyawarah, rapat kerja. Komunikasi horizontal merpakan komunikasi yang terjadi antar unit yang berfungsi sebagai koordinasi, sedangkan komunikasi diagonal merupakan komunikasi yang memotong antar unit dalam organisasi yang biasa dilakukan apabila tidak diketemukan saluran komunikasi kebawah, ke atas maupun horizontal.

Komunikasi sangat penting dalam organisasi pendidikan, pihak pimpinan harus menyediakan ruang yang cukup agar komunikasi dapat terlaksana tanpa hambatan. Saluran komunikasi baik formal maupun non-formal harus ada dan berfungsi dengan baik agar bagian-bagian dalam organisasi dapat berinteraksi dan bersinergi mencapai tujuan organisasi. Pesan yang terkandung dalam komunikasi apabila tidak tersampaikan dengan baik berakibat fatal karena gagal menangkap makna. Komunikasi formal maupun informal sangat berperan dalam dunia pendidikan. Handayani menyarankan bahwa pimpinan sekolah harus meningkatkan komunikasi informal, memilih model komunikasi yang tepat serta memanfaatkan komponen-komponen komunikasi untuk mencapai tujuan. Komunikasi bukan hanya diperlukan bagi kepala sekolah untuk menyampaikan pesan, tetapi juga para guru agar dapat terjalin komunikasi dua arah yang konstruktif dan terbuka.

Guru harus memanfaatkan komunikasi informal untuk meningkatkan kemampuan dan semua warga sekolah perlu menyesuaikan dengan komunikasi organisasi yang ada agar mempunyai persepsi yang sama. ${ }^{3}$ Sebagai institusi sosial, lembaga pendidikan memerlukan kombinasi model-model komunikasi yang paling sesuai dengan kondisi dan karakteristik semua anggota organisasi. Oleh karena itu semua fungsi manajemen harus disertai dengan adanya komunikasi efektif agar semua pesan tersampaikan dengan baik. Fungsi manajemen secara umum adalah planning, organizing, actuating dan cotrolling, semua fungsi ini dapat dimaksimalkan apabila didalamnya terdapat komunikasi yang baik antar unit dan warga sekolah. Komunikasi tersebut tentu saja dilakukan dengan memilih model paling sesuai dengan budaya dan nilai yang dianut oleh lembaga pendidikan.

\footnotetext{
${ }^{3}$ Handayani, S. (2017). Peningkatan Profesional Guru Melalui Komunikasi Informal. SekolahDasar: Kajian Teoridan Praktik Pendidikan, 24(1), h.96.
} 


\section{Al-Hikmah: Jurnal Dakwah, Volume 12, Nomor 2, Tahun 2018 \\ [P. 296-306]}

Penelitian Handayani menemukan bahwa komunikasi informal sangat membantu integrasi dan sinergi semua fungsi manajemen dan juga semua unit terkait pencapaian tujuan bersama. Komunikasi informal sangat penting dilakukan untuk dapat menjangkau data dan informasi yang tidak tersampaikan dalam pertemuan formal.

Komunikasi harus diupayakan maksimal dengan menemukan dan menggunakan jalan tercepat komunikasi dengan anggota organisasi di sekolah agar mendapatkan umpan balik atas-bawah, horizontal dan diagonal sehingga diperoleh informasi cepat, akurat dan terpercaya. Informasi yang sudah didapatkan selanjutnya diolah, dianalisis dan dijadikan bahan untuk perencanan selanjutnya. Pada organisasi pendidikan, seringkali komunikasi informal lebih kuat pengaruhnya daripada komunikasi formal bahkan tak jarang komunikasi formal hanyalah formalisasi dari komunikasi informal.

Organisasi yang mengalami masalah dalam komunikasi akan terhambat kinerjanya dan tidak efektif karena adanya keterlambatan dan ketidaksesuaian yang diinginkan dalam pesan dengan yang diterima. Komunikasi organisasi turut menentukan iklim dan budaya organisasi yang merupakan puncak dari berbagai nilai yang dianut dan menjadi kepercayaan bersama dalam organisasi. Budaya organisasi harus terwujud, dipertahankan dan dipakai bersama dan didukung oleh komunikasi yang baik. Artikel ini ingin mengungkap dua hal, upaya yang dapat dilakukan oleh pimpinan Lembaga Pendidikan Islam untuk mengupayakan komunikasi efektif danbentuk komunikasi efektif pada lembaga pendidikan Islam.

\section{TEORI-TEORI KOMUNIKASI}

Fungsi teori adalah sebagai orientasi yang mempersempit wilayah kajian dengan memberikan batasanbatasan, hubungan, konsep dan juga bisa memprediksi suatu fenomena. Teori bisa menjadi alat analisis (tools of analysis) dan juga bisa menjadi tujuan. Tulisan ini fokus pada upaya komunikasi efektif dan bentukbentuk komunikasi efektif yang dilakukan pada lembaga pendidikan. Oleh karena itu diperlukan teori yang sesuai dan dapat digunakan sebagai pisau analisisnya. Dari sisi teori, sebenarnya banyak teori komunikasi yang digunakan sebagai alat analisis, diantaranya adalah teori agenda setting dari McCombs, teori ketergantungan (dependency theory), teori penerapan nilai, teori informasi atau teori matematis dan sebagainya. Namun dalam artikel ini hanya beberapa teori yang paling relevan saja yang dipakai sebagai alat analisis. Di antara teori penting dalam 


\section{Imron Muttaqin}

Komunikasi dan Dakwah Pada Lembaga Pendidikan Islam

komunikasi adalah teori public relation, teori ini merupakan teori khas dalam organisasi sosial karena dapat berfungsi melakukan evaluasi terhadap sikap publik, melakukan identifikasi terhadap kebijakan dan hasilnya menurut persepsi masyarakat menggunakan komunikasi dua arah. Maksud komunikasi dua arah adalah komunikasi timbal balik antara penyampai pesan dan obyeknya. Paul W. Garrett mengatakan bahwa public relation merupakan sikap mendasar yang dengan mandiri dan sengaja menempatkan masyarakat luas sebagai ukuran dan pertimbangan pada tahap pengambilan keputusan organisasi.Komunikasi dalam dunia pendidikan merupakan bentuk transformasi informasi dari warga sekolah satu dengan lainnya. ${ }^{4}$ Komunikasi ini bisa terjadi antara guru dengan pimpinan/kepala sekolah atau dengan siswa yang diajarnya.

Komunikasi akan membentuk sistem sosial dalam organisasi pendidikan, sistem ini akan mempengaruhi bagaimana komunikasi dalam organisasi itu terjadi serta menentukan arah dari dan kepada siapa komunikasi itu ada. Komunikasi bisa ditingkatkan dengan mengurangi arah komunikasi vertikal yang terkesan hierarkhis dan kaku, sebagai gantinya perlu memperbanyak komunikasi individual

\footnotetext{
${ }^{4}$ Moore, Frazier.2005 HUMAS: Membangun Citra denganKomunikasi. Bandung : PT RemajaRosdakarya, h.7.
}

dalam rangka mendapatkan informasi secara mendalam. Pada pelaksanaannya komunikasi ini diperlukan intensitas kontak yang cukup sering yang mengisyaratkan adanya tranformasi individu dan organisasi sudah terwujud dengan lebih baik, dan yang paling penting adalah adanya saling percaya dalam organisasi.

Berdasarkan topik penelitian ini, maka dipilih teori komunikasi organisasi sebabagai alat analisisnya, komunikasi organisasi adalah pengiriman dan penerimaan pesan yang dikirim dan diterima dalam suatu kelompok dalam organisasi baik yang dilakukan secara format maupun informal. Komuikasi formal dibentuk berdasarkan kesepatakan dalam organisasi yang bentuknya bias kebijakan, memo, jumpapers, surat resmi, pernyataan sikap, instruksi dan surat edaran. Komunikasi informal organisasi tidak berorientasi pada organisasi tetapi lebih mengarah pada komunikasi antar pribadi dalam organisasi.

\section{METODE}

Penelitian ini merupakan studi literatur yang dilakukan dengan menela'ah teori-teori yang relevan melalui buku-buku komunikasi, selain itu juga dilakukan penelaahan terhadap jurnal ilmiah terkait dengan upaya komunikasi efektif dan 


\section{Al-Hikmah: Jurnal Dakwah, Volume 12, Nomor 2, Tahun 2018 \\ [P. 296-306]}

bentuk-bentuknya yang bisa dilakukan pada lembaga pendidikan Islam. Adapun jurnal-jurnal yang ditela'ah diperoleh dari google scholar dan Perpustakaan Nasional Elektronik Republik Indonesia. Penelitian ini bukan bermaksud menguji pemikiran seseroang dalam buku literatur, tetapi bermaksud mengetahui tingkat keterbacaan pemikiran seseorang yang ada dalam buku literatur atau untuk menentukan tingkat pemahaman terhadap teks. ${ }^{5}$

Tahapan proses dilakukan dengan beberapa langkah; pertama, menetapkan beberapa buku terkait dengan topik penelitian, kedua, mencari data pokok/ primer dan ketiga, pencarian pengetahuan kontekstual agar penelitian yang dilakukan tidak berada di ruang hampa tetapi terlihat interrelasi dan interkoneksinya dengan bidang-bidang dan penelitian lain.

\section{PEMBAHASAN}

Berikutnya akan dibahas mengenai upaya komunikasi efektif dan bentukbentuk komunikasi efektif yang perlu dilaksanakan pada lembaga pendidikan Islam. Secara berurutan, akan dibahas upaya komunikasi efektif dan bentukbentuknya serta diskusi teoritis dengan beberap teori komunikasi yang digunakan sebagai tools of analysis dalam artikel ini.

\footnotetext{
${ }^{5}$ MudjiaRahardjo, Jenis dan Metode Penelitian Kualitatif, Tuesday, 01 June 2010 04:52
}

\section{UPAYA KOMUNIKASI EFEKTIF}

Mc. Crosky Larson menjelaskan bahwa komunikasi efektif bisa diupayakan dengan mengutamakan ketepatan tinggi dalam berkomunikasi. Ketepatan ini bisa dicapai dengan kejelasan maksud dan tujuan, berbicara secara tegas, berempati terhadap komunikan, saling menghargai dan mendengarkan dengan baik. ${ }^{6}$ Dalam komunikasi efektif, banyak hal yang harus diperhatikan yaitu empati, sikap positif dan saling mendukung, mengupayakan kesetaraan antara komunikan dengan komunikator. Komunikasi efektif ini bisa diupayakan dengan adanya komunikasi timbal balik dan saling menghargai antara komunikan dan komunee, selain itu pesan yang disampaikan harus jelas dan mudah dicerna serta dipahami, menggunakan cara yang mudah diterima, memperhatikan etika dan norma yang berlaku juga bisa disertai dengan humor. Selain itu, upaya komunikasi efektif juga bisa dilakukan secara non-verbal dengan menekankan pada penampilan fisik, ekspresi dan memberikan sentuhan.

Komunikasi efektif dilakukan dengan memanfaatkan unsur-unsur penting dan elemen penting komunikasi. Komunikasi ini mempunyai ciri memudah-

${ }^{6}$ Onong U, Effendy. 2003. Ilmu, Teori dan Filsafat Komunikasi. PT. Citra Aditya: Bandung, h.68-69. 


\section{Imron Muttaqin}

Komunikasi dan Dakwah Pada Lembaga Pendidikan Islam

kan orang untuk menerima dan menyampaikan pesan. Komunikasi efektif dapat dilakukan dengan upaya menggunakan model komunikasi empatik atau yang lebih dikenal dengan The Empathic Change Communication Style (ECCo-Style) yang ditemukan oleh Duren. $^{7}$ Pimpinan pada lembaga pendidikan yang mempunyai kompetensi emosional akan mudah mempengaruhi orang lain. ECCo-Style mempunyai beberapa komponen yang menjadi dimensi pengukurnya, yaitu expressing empathy, being aware of one's own verbal communication, being aware of one's own nonverbal communication, developing reliability and safeness, using anger and anxieties as stimuli for alterations dan praising good work. Enam komponen ini yang harus diupayakan agar dimiliki oleh pimpinan lembaga pendidikan agar komunikasi tetap terjalin dengan baik. Jadi dapat disimpulkan bahwa upaya yang perlu dilakukan adalah membangun empati dengan semua warga pendidikan. Manajemen komunikasi merupakan bagian dari disiplin ilmu komunikasi terapan, oleh karena karakteristik manajemen maupun komunikasi selalu menyesuaikan kondisi dimana diterapkan, maka upaya yang

\footnotetext{
${ }^{7}$ Düren, P. (2016). Change communication can be so simple! the empathic change communication style. Library Management, 37(8), h.398.
}

dilakukan juga tidak sama antar organisasi, namun terdapat upaya yang umum dilakukan. Di antaranya adalah menggunakan ECCo-Style karena sesuai dengan krakteristik dunia pendidikan yang lebih banyak memerlukan keterampilan hidup bersosial. Sebenarnya teori ini merupakan kombinasi dari beberapa keterampilan berempati ditempat kerja yang kemudian dikembangkan dan disinergikan dengan disiplin ilmu yang lain.

Pada sisi lain, organisasi yang besar memerlukan upaya untuk membuka saluran komunikasi horizontal dan diagonal, karena karakteristiknya dimana orang dalam unit bersifat unik sehingga membutuhkan variasi yang banyak dalam komunikasi. Sesuai dengan penelitian Dody Hermana dan Ujang yang memandang penting pimpinan untuk melihat motif kejiwaan disamping kebutuhan berkomunikasi dalam organisasi, ${ }^{8}$ maka dipandang penting pula mengetahui mengetahui dengan seksama situasi psikologis masing-masing anggota dalam organisasi sekolah sehingga dapat ditentukan cara berkomunikasi paling efektif terhadap individu yang bersangkutan.

\footnotetext{
${ }^{8}$ Hermawan, D., \&Barlian, U. C. (2017).

Komunikasi Dalam Organisasi. Jurnal Administrasi Pendidikan, 2(2).
} 


\section{Al-Hikmah: Jurnal Dakwah, Volume 12, Nomor 2, Tahun 2018 \\ [P. 296-306]}

Komunikasi efekti bisa diupayakan dengan memenuhi semua unsur komunikasi, yaitu komunikator, pesan, channel, sumber dan efek serta sumber komunikasi. Apabila semua unsur ini diperhatikan dan dipergunakan maka upaya komunikasi efektif dapat terlaksana mesikupun butuh penyesuaian dengan situasi dan kondisi yang ada. Yodiq memberikan penjelasan bahwa apabila komunikasi diterapkan dalam dunia pendidikan, pimpinan lembaga pendidikan Islam harus terus mengupayakan komunikasi efektif dengan melakukan komunikasi interpersonal agar terwujud kedekatan emosional sehingga memudahkan untuk menyampaikan pesan antara atasan dan bawahan. ${ }^{9}$

Carl Hovland dan Weiss menyebutkan bahwa salah satu penentu dalam komunikasi efektif adalah kredibilitas yang terdiri dari dua unsur, keahlian dan kepercayaan. ${ }^{10}$ Keahlian dalam berkomunikasi dapat dilihat dari kecerdasan, kepintaran dan pengalaman sedangkan kepercayaan dapat dilihat dari kejujuran, orang yang baik hati, beretika, sopan dan ramah dalam berkomunikasi.

\footnotetext{
${ }^{9}$ Yodiq, M. (2016). PeranKomunikasi Interpersonal Kepala Sekolah Terhadap Motivasi Kerja Guru Di Sekolah Menengah Atas Islam Samarinda. e-JurnalIlmuKomunikasi, 4, 24-34, hl. 24.

${ }^{10}$ Onong U, Effendy. 2003. Ilmu, Teori dan Filsafat Komunikasi. PT. Citra Aditya: Bandung, h.48.
}

Beberapa sifat di atas merupakan persyaratan utama keberhasilan komunikasi pada lembaga pendidikan. Tak bisa dipungkiri bahwa komunikan harus mempunyai empati dan serta kejururan, sopan santun dan ramah karena dengan adanya sifat-sifat ini orang yang diajak komunikasi akan merasa aman dan nyaman serta memberikan informasi yang diperlukan bahwa bisa jadi informasi yang diberikan melampaui informasi yang diperlukan.

Kejujuran merupakan salah satu syarat komunikasi yang efektif dan sangat membantu tersampaikannya pesan kepada komunikan dengan baik. Kejujuran akan membuat orang lain yang diajak berkomunikasi mau mengikuti dan melaksanakan pesan-pesan yang disampaikan karena adanya kepercayaan. Penyampaian pesan yang dilakukan dengan lembut, sopan dan tidak memihak akan menambah kredibilitas komunikasi apalagi penyampaian yang dilakukan dengan cara-cara yang lembut. Upaya melakukan komunikasi komunikasi efektif juga bisa dilakukan dengan menghilangkan identitas kita dan menganggap bahwa kita bukanlah seorang ilmuwan, hal ini diperlukan agar orang yang diajak berkomunikasi bersedia untuk menjawab semua yang kita inginkan, ${ }^{11}$ upaya ini sebenarnya merupa-

\footnotetext{
${ }^{11}$ Clegg, B. (2017). Effective Science
} 


\section{Imron Muttaqin}

Komunikasi dan Dakwah Pada Lembaga Pendidikan Islam

kan upaya untuk melakukan empati sebaik mungkin bagi komunikator karena apabila komunikan merasa kurang aman dalam berkomunikasi maka mereka akan tertutup terhadap informasi penting yang mungkin dicari. Tentu saja semua komuikator akan senang apabila mendapatkan banyak informasi yang diperlukan dari komunikan, maka syarat adanya feedback yang baik ini adalah kemampuan berempati dengan komunikan.

Berdasarkan penjelasan diatas dapat disimpulkan bahwa upaya yang dilakukan oleh pimpinan untuk komunikasi serta dakwah yang efektif pada lembaga pendidikan Islam bisa dilakukan dengan meningkatkan keahlian, pengalaman, kemampuan berempati, kejujuran, beretika, sikap sopan santun, kecerdasan emosional dan kecakapan individu dan kredibilitas informasi yang akan disampaikan.

\section{BENTUK KOMUNIKASI EFEKTIF}

Efektif adalah mengerjakan sesuatu dengan benar sesuai dengan target yang diharapkan sebelumnya atau sesuai dengan yang diinginkan. Komunikasi pada lembaga pendidikan Islamsebenarnya merupakan komunikasi dakwah jika ditujukan pada adanya perubahan pada komunikan yang

Communication. Physics World. https://doi. org/10.1088/ 978-0-7503-1170-0. diharapkan oleh komunikator. ${ }^{12}$ Jika dilihat dari sisi teori, banyak bentuk komunikasi efektif yang bisa dilakukan pada lembaga pendidikan, namun tentu saja membutuhkan penyesuaian dengan tujuan dan iklim organisasi pendidikan.

\section{Komunikasi interprofesional-kola-} boratif adalah komunikasi yang terjadi antar disiplin ilmu yang dimiliki oleh suatu organisasi yang dilakukan secara kolaboratif. Penekanan pada kolaboratif sebagai salah satu ciri pada lembaga pendidikan merupakan wujud dari sifat sosial dan humanis warge sekolah. Kolaborasi ini merupakan bagian tak terpisahkan dari komunikasi interprofesional lembaga pendidikan karena dengan terjalinnya komunikasi yang baik antara guru misalnya yang mempunyai disiplin ilmu berbeda maka terjadi saling tegur sapa dan terkait antar materi dan ilmu pengetahuan. Jika sudah terjadi ketersinggungan antar materi, maka terjadilah koneksi dan integrasi meskipun pada awalnya hanya dilakukan secara individu antar guru. Selanjutnya tentu tinggal diarahkan pada integrasi dan saling mengisi oleh lembaga pendidikan.

\section{Komunikasi asosiatif-akomodatif} sebenarnya merupakan bentuk komunikasi

\footnotetext{
${ }^{12}$ Islami, D. I. (2017). Konsep Komunikasi Islam dalam Sudut Pandang Formula Komunikasi Efektif. WACANA, Jurnal Ilmiah Ilmu Komunikasi, 12(1), 40-66.
} 


\section{Al-Hikmah: Jurnal Dakwah, Volume 12, Nomor 2, Tahun 2018 \\ [P. 296-306]}

sosial, tapi karena fungsinya yang saling berhubungan pada lembaga pendidikan dan tak jarang kedua bentuk ini menjadi satu kesatuan maka disebut komunikasi asosiatif-akomodatif. Pada hakekatnya komunikasi asosiatif digunakan untuk berinteraksi antar individu atau kelompok, tetapi karena seringnya terjadi kondisi yang diterima dan yang dihadapi bersamaan dengan situasi yang disampaikan maka kedua istilah digabung menjadi komunikasi asosiatif-akomodatif.

Komunikasi ini merupakan komunikasi yang berfungsi sebagai perekat antar warga sekolah, oleh karena itu dalam komunikasi ini dicirikan dengan adanya saling menghormati dan saling mendukung.

Komunikasi Interpersonal pada dunia pendidikan sangat penting dan bermanfaat, misalnya komunikasi interpersonal antara kepala sekolah dan guru. Jenis komunikasi antar pribadi ini akan menjadi saluran alternatif apabila pilhan komunikasi sosial, vertikal dan horizontal tidak memungkinkan untuk dilaksanakan. Komunikasi efektif pada lembaga pendidikan Islam harus memperhatikan isi, target, antisipasi dampak, pendukung, metode penyampaian yang tepat, mempunyai lebih dari satu satu tujuan, serta terintegrasi dengan sistem pengawasan. Perhatian terhadap isi/konten yang akan dikomunikasikan perlu dilakukan dengan membuat analisis terlebih dahulu terhadap isi pesan yang akan disampaikan, analisis ini perlu dilakukan dengan mengajak stakeholder dominan atau rekan kerja yang mempunyai pengetauan lebih terhadap isi pesan yang akan disampaikan. Analisis ini juga mencakup target komunikasi, jadi ada segmentasi terlebih dahulu mengguakan mapping pada saat analisis. Orang yang sudah terbiasa menggunakan analisis dalam setiap komunikasinya akan lebih bijak dan diterima argumentasinya karena sudah dipersiapkan dengan baik.

Komunikasi para organisasi pendidikan sangat berpengaruh terhadap semua unsur dan proses manajemen, titik sentral kesuksesan lembaga pendidikan terletak pada komunikasi yang baik semua stakeholder yang turut mempengaruhi perkembangannya. Adanya komunikasi yang baik akan menambah kepercayaan masyarakat terhadap eksistensi lembaga pendidikan, selain itu akan membantu promosi lembaga ke masyarakat dengan baik.

Oleh karena itu komunikasi harus dipahami dan diimplementasikan oleh semua anggota pada lembaga pendidikan. Aris Febri Rahmmanto mengatakan bahwa semua bentuk komukasi pada dasarnya merupakan proses yang menyangkut kepribadian, sikap dan perilaku orang- 


\section{Imron Muttaqin}

Komunikasi dan Dakwah Pada Lembaga Pendidikan Islam

orang yang terlibat dalam organisasi, ${ }^{13}$ selain itu juga perlu bagi organisasi untuk melakukan komunikasi persuasif dua arah serta memberikan motivasi terhadap anggota organisasi.

\section{KESIMPULAN}

Komunikasi dan dakwah sangat berperan pada kesuksesan lembaga pendidikan Islam komunikasi merupakan proses penyampaian ide, gagasan baik yang bersifat horizontal, vertikal atau diagonal. Upaya komunikasi yang efektif dapat dilakukan dengan memenuhi semua unsur komunikasi yang terdiri atas komunikator, pesan, channel, sumber, efek serta sumber komunikasi. Selain itu perlu melakukan pendekatan persuasif dan kedekatan emosioanal dengan meingkatkan keahlian berkomunikasi dan berdakwah pada lingkungan pendidikan. Bentuk komunikasi efektif pada lembaga pendidikan adalah komunikasi interprofesionalkolaboratif, komunikasi asosiatif-akomodatif dan interpersonal. Lembaga pendidikan Islam harus mampu mengkombinasikan berbagai bentuk komunikasi sesuai dengan karakteristik dan budaya organisasi yang dipakai.

${ }^{13}$ Aris Febri Rahmanto. (2004). Peranan Komunikasi Dalam Organisasi. Jurnal Komunikologi. https://doi.org/10.1016/ j.ntt.2003. 10.009

\section{DAFTAR PUSTAKA}

Düren, P. (2016). Change communication can be so simple! the empathic change communication style. Library Management, 37(8).

Gibson, James L, John M. Ivancevic, Hames H. Donnely, Jr. 1997. Organisasi, Perilaku-Struktur-Proses), Edisi 8. Jilid 2. Terjemahan Nunuk Adrinani Jakarta: Bina Rupa Aksara.

Gustavsen, Bjorn. 1992. Dialogue and Development: Theory of Communication, Action Research and the Restructuring of Working Life. Van Gorcum.

Handayani, S. (2017). Peningkatan Profesional Guru Melalui Komunikasi Informal. Sekolah Dasar: Kajian Teori dan Praktik Pendidikan (1).

Hargie, Owen. 2011. Skilled Interpersonal Communication: Research, Theory and Practice, 5th Edition. Routledge.

Hermawan, D., \& Barlian, U. C. (2017). Komunikasi Dalam Organisasi. Jurnal Administrasi Pendidikan (2).

Holmes, David. 2005. Communication Theory: Media, Technology and Society. SAGE Publications.

Islami, D. I. (2017). Konsep Komunikasi Islam dalam Sudut Pandang Formula Komunikasi Efektif. WACANA, Jurnal Ilmiah Ilmu Komunikasi (1).

J. Albers, Michael. 2004. Communication of Complex Information User Goals and Information Needs for Dynamic Web Information. Routledge.

Lawrence Heath, Robert, Jennings Bryant. 2000. Human communication theo- 
ry and research: concepts, contexts, and challenges. Routledge.

Miftah, M., \& Semarang-PustekkomDepdiknas, B. P. M. (2009). Komunikasi Efektif Dalam Pembelajaran. Semarang: Pustekkom Depdiknas.

S. Lyons, John. 2009. Communimetrics: A Communication Theory of Measurement in Human Service Settings. New York. SpringerVerlag.

Wijaya, D. K., \&Herminingsih, A. (2015). Pentingnya Komunikasi Organisasi, Motivasi Kerjadan Kompensasi untuk Meningkatkan Kinerja Guru. JEAM Vol. XIV. ISSN: 1412-5366 e-ISSN: 2459, 9816.

Yodiq, M. (2016). PeranKomunikasi Interpersonal Kepala Sekolah Terhadap Motivasi Kerja Guru Di Sekolah Menengah Atas Islam Samarinda. e-Jurnal Ilmu Komunikasi.

Canary, Heather E., Robert D. Mc.Phee. 2010. Communication and Organizational Knowledge: Contemporary Issues for Theory and Practice (Routledge Communication Series).

Aris Febri Rahmanto. (2004). Peranan Komunikasi Dalam Organisasi. Jurnal Komunikologi. https://doi.org/ 10.1016/j.ntt.2003.10.009

Clegg, B. (2017). Effective Science Communication. Physics World. https://doi.org/10.1088/978-0-75031170-0.

Moore, Frazier. 2005. HUMAS: Membangun Citra dengan Komunikasi. Bandung: PT Remaja Rosdakarya.

Effendy Onong U,. 2003. Ilmu, Teori dan Filsafat Komunikasi. PT. Citra Aditya: Bandung. 
Imron Muttaqin

Komunikasi dan Dakwah Pada Lembaga Pendidikan Islam

306 